\title{
Will a catch share for whales improve social welfare?
}

Martin D. Smith ${ }^{1,2}$, Frank Asche ${ }^{3}$, Lori S. Bennear ${ }^{1,2,4}$, Elizabeth Havice ${ }^{5}$, Andrew J. Read ${ }^{6}$, and Dale Squires $^{7}$

1. Nicholas School of the Environment, Duke University, Box 90328, Durham, NC 27701, USA

2. Department of Economics, Duke University

3. Department of Industrial Economics, University of Stavanger, 4036 Stavanger, Norway

4. Sanford School of Public Policy, Duke University

5. Department of Geography, University of North Carolina-Chapel Hill, Saunders Hall, Campus Box 3220, Chapel Hill, NC 27599-3220, USA

6. Duke Marine Lab, Nicholas School of the Environment, Duke University, 135 Duke Marine Lab Road Beaufort, NC 28516, USA

7. NOAA Southwest Fisheries Science Center, 8604 La Jolla Shores Drive, La Jolla, CA 92037-1023, USA

* Corresponding author. Email: marsmith@ duke.edu, ph: (919) 613-8028, fax: (919) 684-8071 
Gerber, Costello, and Gaines (GCG) propose using catch share markets for conservation of wildlife. The rationale for a tradable quota system draws on the logic of catch shares to manage fisheries harvest and permit trading to control air and water pollution. In many cases, such systems have improved management and lowered costs. GCG argue that catch shares can also lead to efficient conservation outcomes by allowing environmental groups (NGOs) to purchase and retire permits and thereby reduce the commercial harvest activity. They investigate the potential to generate conservation gains through a catch share system to manage whales.

It is well established that creating tradable quota markets can be an effective tool for environmental management, although the success of the market (e.g. 'effectiveness') depends on a range of factors including the institutional setting, the policy design, the specific environmental issue in question, and whose values and definitions of 'effective outcomes' such programs are based upon. The purpose of this paper is to highlight features that would influence the outcome of introducing a quota for whales that GCG do not address. These concerns are applicable for other possible uses of wildlife conservation markets such as elephants, tigers, and birds that are largely transboundardy and require multilateral conservation approaches. We argue that the choice to use whales to develop a model for market based conservation requires engagement with the specifics of whales and whale management. More generally, any market approach to conservation should carefully consider the specifics of the case in question to ensure that the appropriate conservation tool is selected and applied.

There are two distinct strands to our critique of GCG's analysis. The first strand focuses on GCG's novel use of the market to incorporate conservation values as a method for determining the level of conservation. We argue that this is akin to using the market to set the "cap" rather than solely using the market to allocate permits under the cap. Use of market-based mechanisms 
to both set the level of harvest and allocate that harvest has never been tried before and its success hinges critically on the ability of the market to accurately reflect all values of the managed species, both for private consumption and public conservation. This is particularly problematic because most wildlife to which their model may apply, including their example of whales, are impure public goods that require multilateral conservation across jurisdictions and multiple states. In economics, we use the term impure public goods to refer to goods that generate both private value for an individual consumer or firm (e.g. someone who eats whale meat or harvests whales) and public value that is shared by all consumers (e.g. the intrinsic value of keeping a whale in the ocean).

To illustrate the concept further, consider the choice between an organically grown apple and a conventionally grown apple sprayed with pesticides. We consider the organic apple an impure public good because it provides private value to the consumer in the form of enjoyment, nutrition from eating the apple, and potential health benefits from avoiding pesticide residues. But it also provides public value in the form of avoided pesticide runoff that, in turn, benefits the ecosystem downstream. These ecosystem benefits are enjoyed by all consumers and not just by the purchaser of the apple. The impure public goods feature of whales has important ramifications for the outcome of the modeling exercise in GCG because this feature makes it difficult to raise funds to reflect the full value of conservation.

The second strand of critique focuses on four implementation issues that relate more specifically to whales that are not accounted for in GCG's proposal and model; similar issues emerge for other internationally shared wildlife populations. First, the creation of a whale share would legitimize the international trade in whale meat, which could expand the whale meat market. Consumers of whale products would be better off, but individuals who value whale 
conservation would be worse off because it becomes harder for conservationists to buy out quota and represent conservation values in the market. Second, a legal whale trade creates monitoring and enforcement challenges similar to those of organizations that manage highly migratory species like tuna and exotic threatened species like rhinoceros. The market for whale products may or may not expand in size, but it will be qualitatively different. Third, introducing a catch share will likely create a new political economy of management that could change incentives and make it significantly more costly for NGOs to achieve the current level of conservation. Unlike market legitimization on the demand side, this feature may add pressure to increase harvest and expand the market for whale products from the supply side. The political economy of management is considerably more complicated in international arenas than in national settings where quota systems are most commonly used. Fourth, a whale share program creates new logistical challenges for quota definition and allocation regardless of whether the market for whale products expands or contracts. For instance, should the quota be set to achieve MSY? Most fisheries management defaults to this objective, including the U.S. Magnuson-Stevens Fishery Conservation and Management Act.

We assess the relevance of each of these issues to GCG's proposal as applied to whales, drawing on relevant examples and issues for international fisheries of high value such as the management of tuna stocks with Regional Fisheries Management Organizations (RFMOs). Tuna RFMOs, while a clear improvement over no international management efforts, highlight some of the challenges that a whale shares program would likely face. We assert that controlling these issues is outside of the scope of the proposed conservation tool (a quota system). Each issue, if left unaddressed, could generate lower overall welfare for society and potentially greater threats 
to marine mammal conservation than the status quo, complicating GCG's assertion that the quota system will definitively yield maximum efficiency.

Our analysis is neither prescriptive nor empirical - that is, we are not asserting that any one outcome will come to fruition - rather it is designed to highlight that the use of quotas for conservation is not a black and white issue, and that treating it as such in the whale context obscures the relevance of the contested international politics and economics that have driven calls for alternative solutions to the fragile IWC ban in the first place.

We begin with an overarching critique of GCG's proposal for the use of cap-and-trade programs for conservation. Our critique hinges on the fact that catch share programs (aka ITQs) and other cap-and-trade systems are not designed to set an efficient cap; they rely on the ability of a regulatory agency or organization to set and enforce the cap (for fisheries, this is the total allowable catch) and rely on the market to allocate the shares under that cap. Using the market to allocate resources under a cap, for pollution or for fish, can improve management and lower costs (Stavins 1998, Grafton 1996, Costello, Gaines, and Lynham 2008). However, catch shares do not address optimal management of whole ecosystems (Arnason 2012), and apparent biological gains from catch shares may be attributable other factors, namely the cap itself (as opposed to the trading) (Bromley 2009) or changes in reporting systems (Nowliss and Van Benthem 2012). Comparing fisheries with catch shares to fisheries with just caps suggests no gains in mean biological reference points but benefits in the form reduced variability (Essington 2010). Above all, having a binding cap that reduces pollution or fishing mortality is critical to gain support for these programs from environmental groups (Chan, Stavins, Stowe, \& Sweeney, 2012; Keohane, Revesz, \& Stavins, 1998; Stavins, 1998). 
GCG are proposing something different: allow the setting of the cap based on some unspecified scientific criteria and then use the market to shift the actual harvest level to approximate the socially efficient harvest level. While some cap-and-trade pollution permit systems - in particular the program regulating $\mathrm{SO} 2$ emissions in the United States-allow environmental groups to purchase permits and retire them, no system of tradable permits has ever relied on this mechanism to determine where the cap should be. Retirement of SO2 permits has been low, not because environmentalists do not care about SO2 pollution, but because they successfully lobbied for a binding cap in the first place. In short, prior catch share and cap-andtrade systems have been used to reach an agreed upon cap cost-effectively; they have not been used to try to assess where the efficient cap should be.

GCG's proposal to use the market to determine the level of conservation and the level of consumption hinges on the ability of the market to reflect demand for conservation accurately. However, this outcome is questionable because most conservation goods, including whales, are impure public goods (Kuronuma and Tisdell 1993) that have features of private and public goods. Consumption of whales has private features because a whale harvested by one vessel cannot be harvested again by another. In contrast, a public good can be enjoyed by many (or all) individuals simultaneously. Whales also meet this definition in that more than one individual may simultaneously value the existence of the same whale. So, when a whale is harvested, its existence value is lost not just by one consumer but by all consumers. Similar claims could be made for other charismatic marine and terrestrial species. Moreover, multiple individuals can enjoy viewing the same whale on a whale watching trip (either simultaneously or on separate trips). Harvesting a whale is a loss to not just one whale watcher but to all whale watchers who may see this animal. For public goods, the total value of a unit is the sum of values across all 
individuals. The policy problem resulting from public goods is that too few of these goods will be produced by the free market because of free-rider and collective action problems.

The free-rider problem is one where individuals do not pay their true values because they can still gain use of the resource even if they do not pay for it-they can free ride on the contributions of others and there are benefits external to the provider (Samuelson 1954). Consider, for example, an individual who values air quality and has a choice between taking the bus to work or driving a private car. The car will produce more pollution and lower the air quality relative to the bus, but driving the car is less costly to the individual because she can get to work faster. For the individual, the benefit to the environment of taking the bus is imperceptibly small, but the cost (in terms of time) is noticeable, so the individual often will choose the dirty alternative and drive to work. The problem is that that imperceptibly small benefit to the environment is a benefit to everyone and not just the individual making the choice. But the incentives are set up for her to ignore the benefits to others and let others choose the cleaner alternative. Because many other consumers follow the same logic, the air quality ends up being lower than everyone would agree it should be. This is the essence of the free rider problem.

The collective action problem results from difficulty in coordinating individuals and pooling resources for public goods provision. Consider the car and bus choice again. People do not want to choose the bus alternative to get a tiny increase in air quality, but they might be willing to do it if there were a substantial increase in air quality. If everyone coordinated and took the bus, the air quality would be substantially improved. This is the collective action problem. Correcting the free-rider and collective action problems typically requires government provision and taxation. Catch share programs do not correct free-rider or collective action problems for public goods 
provision. Even sole ownership or privatization of an impure public good does not ensure the efficient outcome, as private interests could diverge from social interests and drive a stock to extinction (Clark 1973).

GCG acknowledge the public goods nature of conservation and the potential for free riding. They suggest that their proposed catch share program could address the public goods problem by allowing environmental NGOs the opportunity to use funds to purchase shares, thereby reflecting public demand for conservation. However, this ex-post incorporation of conservation demands through the free market is unlikely to result in an efficient level of whaling, as it will include private demand only, not social demand for conservation. Private demand reflects voluntary contributions to a public good summed across individuals (donations to NGOs in this case). These contributions reflect free-riding and understate total social demand, which captures the total value to society of the public good. For species that are less charismatic than whales, we would expect the extent of free-riding to be more severe, suggesting even more limitations of the use of catch shares to conserve non-extractive uses of wildlife.

Figure 1 illustrates this point using the market for whale shares as an example. The figure demonstrates that the market would underprovide whale conservation because the private demand (i.e. demand reflecting voluntary contributions to NGOs) lies below the social demand. Consistent with GCG, we assume that the International Whaling Commission (IWC) or another institution sets a safe minimum population level and that this population is at least as large as the population that produces MSY. As such, equilibrium harvest is strictly decreasing in the whale population; as population increases from the MSY-level toward carrying capacity, the surplus production available for harvest decreases. Allowing NGOs to raise funds for conservation and 
purchase shares would result in a stock of whales at the market equilibrium that is below the social optimum.

One might argue that the free-rider problem is small for whales. GCG suggest that this may be true because voluntary contributions to whale conservation appear high in absolute terms, perhaps indicating that NGOs have successfully gotten contributors to donate close to their true values. However, large contributions do not necessarily indicate that NGOs have overcome free riding because NGOs have no sovereign authority to tax; large contributions could mean that NGOs have raised a small fraction of a very large social demand for conservation. Consistent with a potentially very large willingness to pay for whale conservation, Lew et al. (2010) show that willingness to pay for conservation of another marine mammal, Steller sea lion, is in the range of $\$ 10$ billion per year for U.S. households. If NGOs were able to raise this level of funding for each whale species and other species of wildlife managed with catch shares, the issue of free riding would be much less of a concern.

The use of a market to establish the level of harvest could be efficient if there were some mechanism to capture consumer's true willingness to pay for conservation. In other contexts, such as water markets, this mechanism has not materialized; allocation of water to the environment is done by government (not NGOs), and water trading is a means to allocate what is left for agricultural and municipal uses cost-effectively. Debates about wildlife catch shares thus mirror debates about water trading: "attention must be paid to water's unique and public good characteristics. Those who caution against haphazard market formation are not necessarily opponents; once basic uses of water (human and environmental water needs) are met, water markets are an efficient mechanism for dealing with the scarcity of the remaining elective uses of water" (Chong and Sunding, 2006, p. 260). 
As one of the few acceptable deviations from the IWC moratorium on whaling, aboriginal subsistence whaling (ASW) raises a different set of public goods issues. ASW is acceptable because whaling is essential to maintain these cultures, so cultures themselves become public goods in the discourse. Under the current IWC, these cultural public goods are deemed more desirable than the environmental public goods lost from whales taken by ASW. GCG make a distinction between two different uses of whales when stating, "If we assume that there is an extremely high value to harvest even a few whales, the choke price grows, suggesting that the ASW will not sell all quota to conservationists" (p. 13). GCG do not appear to acknowledge the public good nature of the aboriginal whaling as a means to maintain the culture and the world's value of these cultures. The rest of the world attaches some value to preservation of aboriginal cultures and not just members of aboriginal societies.

A separate but related question is whether cultural heritage of commercial whaling has a public good component. The past decisions of IWC suggest that allocation of quota to aboriginals is acceptable, but it is not acceptable to sustain coastal cultures by allowing whaling in modern societies like Japan and Norway. This record reinforces our claim that the only reason for allocating whale quotas for ASW is the public good aspect. If any group that has been allocated quota under these circumstances has anything to sell, this implies that the IWC has awarded them too much quota or that the aboriginals are willing to give up their culture for a large enough sum of money while the international society will not let them. This potential conflict raises questions of sovereignty that are beyond our scope.

We now turn to the second strand of our critique, which emphasizes four implementation issues specific to the GCG proposal as applied to whales, but with broad relevance to international wildlife conservation. First, a resumption of internationally sanctioned whaling 
beyond indigenous and scientific use could stimulate demand for whale meat and other products. Currently, whales are caught and commercially consumed in only four countries, Iceland, Japan, Norway and South Korea. All whales are listed by CITES such that trade is illegal except for countries entering "reservations" (http://www.cites.org/eng/app/reserve_intro.php). With legal harvesting under sustainable management, whale meat could expand into new markets. A counterpoint to this concern is the claim that the general decline in market value of whale products is largely responsible for stabilized whale populations (Schneider and Pearce 2004).

Other species provide examples of the power of increased demand. In fisheries, Atlantic Bluefin tuna illustrates both sides of the issue. Prior to the 1970s, a commercial fishery for Atlantic Bluefin tuna did not exist in the U.S. because the U.S. did not have access to the Japanese market (Bestor 2001). Technological innovations and changing trade relations allowed a growing U.S. fishery to access the high-value Japanese market, generating significant fishery values. When the Japanese economy weakened in the 1990s, a domestic U.S. market emerged in conjunction with growing U.S. consumer taste for sushi (Bestor 2001). Now Atlantic Bluefin face significant conservation challenges. Would society have been better off without the development of the fishery and diffusion of taste for sushi tuna? The answer depends in part on whether the charismatic Bluefin contribute significant value as public goods and whether these values outweigh the expanded private values from sushi tuna consumption. Product development, improved logistics, and better refrigeration similarly have expanded global markets for many other seafood species (Asche et al. 2011), albeit ones that do not appear to be as charismatic as elephants, whales, and Atlantic Bluefin.

There are two mechanisms through which market legitimization could stimulate demand and lower welfare. The first is the concept of experience goods: consumers tend to consume more of 
products with which they have experience. Currently, consumers in most of the world have no opportunity to experience whale products, but they may gain these opportunities under a whale shares program. There has been dramatic globalization of the international seafood trade in the past several decades (Smith et al. 2010), suggesting possibilities for trade in whale products are far greater than they were before the IWC moratorium. There are competing behavioral explanations for the experience goods phenomenon. One is that consumer tastes are malleable and can be shaped by framing and other manipulations of marketers (Thaler and Sunstein 2008). The other explanation is that consumer tastes for product attributes are unchanging, but by trying new products people gain knowledge or appreciation for the attributes of a product and then demand more (Stigler and Becker 1977). We do not take sides in this behavioral debate but point out that both views support the possibility of increased market demand for whale products. Although the current demand for whale meat in Japan is relatively small, there exists a high-end premium market (Onozaka and Uchida 2011). Whether consumer interest in whale meat would diffuse internationally as consumers gain access to experience eating whales is an open question, but experiences with sushi products suggest this possibility.

The second mechanism through which market legitimization could stimulate demand and lower welfare is how the creation of a price for whale would affect consumer social norms. Currently, there is no whale meat price for consumers in most of the world. Behavioral economists have shown that creating a price for something where previously behavior was regulated by social norms can have the unintended consequence of increasing consumption. A classic example is the use of late fees in Israeli daycares; when there were no late fees, parents were more likely to pick up their kids on time, so creating the price incentive backfired (Gneezy 
and Rustichini 2000). A whale share effectively prices whales where no prices existed before, and this pricing may send a signal that consumption is socially acceptable.

Despite the potential benefits to consumers when demand for whale products increases, overall social welfare can decrease (Figure 1(b)). Any growth in private demand, holding everything else constant, could only lead to harvesting more whales in equilibrium. This outcome will always lower social welfare as long as the public goods value of conserving an additional whale exceeds the private value of consuming it.

Our second implementation critique is that creation of a whale share program will legitimize whaling in the international community and create new monitoring and enforcement challenges. Under the status quo, there is very limited legal international trade in whale products; whale products traded internationally are illegal other than trades between countries registering reservations under CITES. A legal trade in whale products would raise the many challenges associated with controlling illegal, unreported, and unregulated (IUU) fishing (Sumaila, Alder, and Keith 2006). Among these is the difficulty distinguishing between legally caught and illegally caught whale meat and other products. Certification would potentially aid in delineating legal and illegal harvest, but this suggests that a well-functioning whale share program would require developing new institutions. Moreover, the efficacy of these new institutions would be a concern, as genetic testing suggests certification in fisheries does not ensure a clean supply chain (Marko, Nance, and Guynn 2011). International management of other charismatic wildlife species faces similar challenges. For example, there is empirical evidence that trade bans for ivory would be more effective in promoting elephant conservation than allowing legal ivory trade despite theoretical arguments for and against bans (Bulte and Van Kooten AJAE 2006). A 
catch share for whales with a trade ban would likely produce very different outcomes than the same catch share without a trade ban.

Figure 1(c) demonstrates how a whale share program creates incentives for illegal harvest. Whale shares decrease social welfare in most scenarios, and social welfare improvements are not attributable to share trading but instead are artifacts of setting safe minimum standards, initial allocations, or, providing perverse incentives for illegal trade.

Enforcement also hinges on the ability of the IWC to set and enforce a cap. In their 2012 paper the authors assert that the IWC is "up to the task" (Costello, Gaines, and Gerber, Nature pg. 140). However, by their own account, since the 1990s and under the auspices of the IWC's moratorium on commercial whaling, the number of whales taken has more than doubled, many populations of whales have been severely depleted and continue to be threatened by what GCG call "largely unregulated" whaling and an IWC "long hamstrung by management and ethics issues" (Costello, Gaines, and Gerber, p. 139). This is important context because the IWC's fragility is the reason that GCC have made their proposal, but the fragility is ignored in their model. Another critical enforcement issue is that rights-based management must be selfenforcing because without a supranational sovereign body, multilateral cooperation, compliance, and enforcement are through voluntary agreement among IWC members (Barrett 2003). A trade that shifts the quota in either direction under GCG's proposal would not require agreement among IWC members, raising questions about the stability of the catch share program.

The above analysis illustrates that there are a number of cases in which a whale share program could lower social welfare. Most importantly, cases in which whale shares would increase welfare are artifacts of setting the cap and not of the trading program. Thus, the dynamics that determine the cap become a crucial dimension for evaluating the potential for a 
whale share program to improve the status quo. To the extent that the current political economy of setting caps in the IWC is problematic, a whale share program does not appear to change this dynamic. Thus our third implementation critique surrounds the political challenges to establishing the cap in an already politically fraught international arena.

A key concern for a new cap and trade program is how implementing a cap and an intention to allocate access and catch rights can generate a scramble to secure a share of the resource. Experience from cooperatively managed tuna fisheries is illustrative. When the International Commission on the Conservation of Atlantic Tunas (ICCAT) was established, Commission members with Bluefin fleets negotiated measures to exclude outsiders and codify historically and geographically determined access rights (Webster 2010). There were few new entrants until ICCAT established country-specific quotas in the mid-1990s. ICCAT membership had hovered between 10 and 20 from 1970-1995, but after the cap was introduced (and tuna value increased) membership jumped dramatically to 48 member countries by 2010 (http://www.iccat.int/en/). Similarly, when the Western and Central Pacific Fisheries Commission (WCPFC) was negotiated, fishing nations in Europe and Latin America that were not regularly active in the region sought membership and participation rights.

While the United Nations Fish Stocks Agreement (UNFSA) establishes that participation in such programs for fish should be open to those with a "real interest," the criterion of "real interest" is not defined in the UNFSA. Real interest has not been defined for whales, and whales may be considered part of the global heritage of humanity in a manner similar to the International Seabed Authority (ISA) and sovereignty and management of the Area. Although there are frameworks that limit participation in Regional Fisheries Management Organizations, the IWC is open to all states, greatly complicating the issues of "real interest," closure, and 
allocation. Do entrants after the initial allocation have legitimate interests in rights and how should they participate? Undoubtedly, entry into the IWC will increase with catch shares, raising issues of recurring reallocation, duration, and divisibility of the right. The resulting uncertainty for rights holders could lower the value of the property rights and hinders investment for both commercial whalers and NGOs. States formally objecting to their allocation might not be bound by any cap. The creation of rights with real value could even prompt a revision to the IWC akin to the ISA in which whales are redefined to constitute part of the global heritage of all states. Whales would then be collectively managed as a global public good, similar to minerals in the deep seabed by the ISA, including payments of royalties and conservation requirements. This is not an argument against whale shares per se but suggests that potential gains are qualitatively different from those modeled in GCG.

Moreover, geopolitical interests that may diverge or be distinct from the management objectives at hand can influence the cap and quota allocation in unpredictable ways, particularly in an international negotiating arena. This dynamic is familiar at the IWC where votes become political capital that small states use to derive economic benefit from those IWC members with vested interest in outcomes (Stringer 2006). Replacing the IWC's fragile moratorium with capand-trade does not guarantee that the geopolitical entanglements that have generated the current stalemate will be eliminated. To draw on one example, geopolitical influences on participation and voting have contributed to frustrated efforts to limit mortality on tuna species at the WCPFC. Further, where effort controls are in place, allocation processes introduce a second layer of geopolitical considerations: fishing nations use management and access negotiations to earn regional influence; offers of aid, investment and infrastructure are reported to reduce the stringency of enforcement (Havice and Campling 2010). 
The fourth implementation issue is that a whale share program creates new logistical challenges for quota definition and allocation regardless of whether the market for whale products expands or contracts. Once whaling is legitimized in the international community, pressure might well grow to manage whale stocks for MSY, the default approach for most fisheries management. While admittedly speculative, such a policy would greatly increase the total allowable catch of whales relative to the status quo for species such as Minke whales and could exacerbate underprovision of public goods as Figure 1 illustrates. To the extent that stocks of other whale species recover, pressure could be brought to open these stocks to harvest.

The selection of whale species subject to a catch share is complex. Harvesting species under rebuilding programs or at critically low population levels can be counter-productive. Catch shares on species with low population levels can mean that the number of vessels exceeds the desired limit, catches are rare events, it is not possible to allocate the total catch across vessels, and group rather than individual rights are required (Segerson 2011). Fleets under whale shares may need to pool shares and coordinate efforts. Whether to specify catch shares to individual species or groups of species (e.g. "blue whale units") raises the rare events problem again and discordance between catch limits and mortality rates for individual species and substitution between species in a composite unit.

Catch rights in international agreements are complicated because they include two rights in a multilateral self-enforcing commission: the catch right and an access right (Squires et al. in press). The access right can be to Exclusive Economic Zones (EEZs) reflecting individual national sovereignty or to the high seas under IWC auspices. The catch right may be bundled with or separate from the access right. Rights may have to be issued first to states and then to individuals because of the sovereignty of states both within their EEZs and as the primary actors 
in the IWC. If rights are first issued to individuals, then states may well assert their sovereignty as with the Inter-American Tropical Tuna Commission's capacity program.

Allocation is the most contentious element of any catch share program. Are rights allocated to nations and then vessels or directly to vessels? Which nations can receive allocations, and do coastal developing states receive particular consideration because of their EEZs in which whales spend all or part of their lives? It is essential to start an allocation of rights by closing the pool of participants to which rights are allocated but allow entry by new states. Limited duration can accommodate entry into the process and mitigates the tensions that otherwise arise when states perceive their sovereignty to have been circumscribed. Compliance and enforcement are necessary components of any allocation agreement, and must be considered as part of the agreement and initial allocation. Because the IWC is voluntary and requires multilateral cooperation for success (Barrett 2003), failure to solve the allocation issue would undermine self-enforcement.

In conclusion, market-based policies like catch shares have an important role to play in marine conservation, but the details are tremendously important particularly in the international arena for global impure public goods. In the case of whale shares, the policy will be unable to achieve a social optimum unless the IWC happens to set the cap close the optimal (though difficult to calculate) level. Only under these circumstances do potential gains from quota trading emerge because NGOs can raise sufficient funds to move the quota. The potential for catch shares to mimic the social optimum is considerably lower for less charismatic species, as NGOs have more difficulty fund raising in these cases. Qualitatively, there are many possible pathways through which the policy would lower social welfare: free riding in the private demand for conservation, stimulating demand for whale products that moves the market outcome further 
from the social optimum, creating new enforcement challenges, and additional pressures on the political economy of setting the cap and allocation of the rights. Catch shares in the international arena face very different circumstances than national programs, and the latter do not simply translate to the international arena. Several key factors differ from national programs: multiple jurisdictions, international law, the sovereignty of nations, and the necessity of self-enforcing multilateral cooperation. Establishing who has "real interest" will be crucial and may well evolve with the introduction of rights.

A successful whale share policy, at minimum, requires a mechanism to collect voluntary contributions to whale conservation that do not fall short of the social demand due to free riding and an enforcement mechanism that can distinguish between legally and illegally traded whale products. In contrast, there are only a handful of pathways through which whale shares would increase social welfare, and these are artifacts of where the cap is set and not attributable to trading shares per se. Nevertheless, no one can say with certainty what the outcome of a whale shares proposal would be for whale stocks and marine conservation more broadly. There is risk in staying with the status quo stalemate, but there is also risk in adopting a new policy approach. Empirically understanding the pathways through which a whale share would increase or decrease social welfare is an important direction for future consideration.

\section{Literature Cited}

Asche, Frank, Roy Dahl, Daniel Gordon, Trine Trollvik and Paul Aandahl. "Demand growth for salmon in the European market.” Marine Resource Economics 26.4 (2011): 255-265.

Arnason, Ragnar. "Property rights in fisheries: How much can Individual Transferable Quotas accomplish?" Review of Environmental Economics and Policy 6.2 (2012): 217-236. 
Barrett, Scott. Environment and Statecraft: The Strategy of Environmental Treaty Making. Oxford, UK, Oxford University Press. (2003)

Bestor, Theodore. "Supply-Side Sushi: Commodity, Market, and the Global City." American Anthropologist 103.1 (2001): 76-95.

Bromley, D. 2009. "Abdicating responsibility: the deceits of fisheries policy." Fisheries 34.6:280-302.

Bulte, E. H., \& Van Kooten, G. C. . Economics of antipoaching enforcement and the ivory trade ban. American Journal of Agricultural Economics 81(1999): 453-466.

Chan, G., Stavins, R., Stowe, R., \& Sweeney, R. "The SO2 Allowance-Trading System And The Clean Air Act Amendments Of 1990: Reflections On 20 Years Of Policy Innovation.” National Tax Journal, 65.2, (2012): 419-452.

Chong, Howard, and David Sunding. "Water markets and trading." Annual Review of Environmental Resources 31 (2006): 239-264.

Costello, Christopher, Steven Gaines, and Leah R. Gerber. "Conservation science: A market approach to saving the whales." Nature 481.7380 (2012): 139-140.

Costello, Christopher, Steven D. Gaines, and John Lynham. "Can catch shares prevent fisheries collapse?." Science 321.5896 (2008): 1678-1681.

Clark, Colin. "The economics of overexploitation." Science 181.4100 (1973): 630.

Essington, T. 2010. "Ecological indicators display reduced variation in North American catch share fisheries." Proceedings of the National Academy of Sciences 107.2:754-759.

Gneezy, Uri, and Aldo Rustichini. "Pay enough or don't pay at all." The Quarterly Journal of Economics 115.3 (2000): 791-810.

Grafton, R. Quentin. "Individual transferable quotas: theory and practice." Reviews in Fish 
Biology and Fisheries 6.1 (1996): 5-20.

Havice, Elizabeth, and Campling, Liam. "Shifting tides in the Western Central Pacific Ocean tuna fishery: The political economy of regulation and industry responses." Global Environmental Politics 10.1 (2010): 89-114.

Keohane, N. O., Revesz, R. L., \& Stavins, R. N. (1998). “Choice of Regulatory Instruments in Environmental Policy.” The Harvard Environmental Law Review 22: 313-367.

Kuronuma, Yoshihiro, and Clement Tisdell. "Institutional management of an international mixed good: the IWC and socially optimal whale harvests." Marine policy 17.4 (1993): 235-250.

Lew, Daniel K., David F. Layton, and Robert D. Rowe. "Valuing enhancements to endangered species protection under alternative baseline futures: the case of the Steller sea lion." Marine Resource Economics 25.2 (2010): 133-154.

Marko, Peter, Holly Nance, and Kimberly Guynn. "Genetic detection of mislabeled fish from a certified sustainable fishery." Current Biology 21.16 (2011): R621-R622.

Nowlis, Josh, and Arthur A. Van Benthem. "Do property rights lead to sustainable catch increases?." Marine Resource Economics 27.1 (2012): 89-105.

Onozaka, Yuko, and Hiro Uchida. "Do Japanese Consumers Really Want to Eat Whales?” Presented at North American Association of Fisheries Economists Forum 2011, May 1113 , Hawaii, U.S.A. (2011).

Samuelson, Paul. "The pure theory of public expenditure." The Review of Economics and Statistics 36.4 (1954): 387-389.

Schneider, Viktoria, and David Pearce. "What saved the whales? An economic analysis of 20th century whaling." Biodiversity and Conservation 13.3 (2004): 543-562. 
Segerson, Kathleen. "Policies to reduce stochastic sea turtle bycatch." Chapter 19 in Peter Dutton, Dale Squires, and Mahuzuddin Ahmed, editors. Conservation of Pacific Sea Turtles. University of Hawaii Press, Honolulu (2011).

Squires, Dale, Robin Allen, and Victor Restreppo. "Rights-Based Management in International Tuna Fisheries." FAO Fisheries and Aquaculture Technical Paper No. 571. Rome: Food and Agriculture Organization of the United Nations (in press).

Stavins, Robert N. (1998). "What can we learn from the grand policy experiment? Lessons from SO2 allowance trading." The Journal of Economic Perspectives, 12.3: 69-88.

Smith, M.D., C.A. Roheim, and 18 others. "Sustainability and Global Seafood.” Science 327 (2010):784-786.

Stigler, George J., and Gary S. Becker. "De gustibus non est disputandum." The American Economic Review 67.2 (1977): 76-90.

Stringer, Kevin. "Pacific Island microstates: Pawns or players in Pacific Rim diplomacy?" Diplomacy \& Statecraft 17.3 (2006): 547-77.

Sumaila, Ussif Rashid, J. Alder, and H. Keith. "Global scope and economics of illegal fishing." Marine Policy 30.6 (2006): 696-703.

Thaler, Richard H., and Cass R. Sunstein. Nudge: Improving decisions about health, wealth, and happiness. Yale University Press, New Haven, CT (2008).

Webster, D. G. "The irony and the exclusivity of Atlantic bluefin tuna management." Marine Policy 35.2 (2010): 249-51. 


\section{Figure Legend}

Figure 1 - Market outcomes and the social optimum. (a) The free market underprovides whale conservation. The market equilibrium for whale shares is at the intersection of Private Demand for Conservation (voluntary contributions to NGOs) and Demand for Whaling where the resulting population is $\mathrm{N} \_$market. The optimal population is at the intersection of Social Demand for Conservation and Demand for Whaling (N_optimal). N_market is above the safe minimum population (N_min) but below N_optimal. A higher Social Demand for Conservation could lead to the optimal population being at carrying capacity $\mathrm{K}$, while a higher Demand for Whaling could lead to a market equilibrium population at N_min. (b) Growth in demand for whale meat exacerbates underprovision of conservation. An increase in demand from Old Demand for Whaling to New Demand for Whaling decreases the equilibrium whale population from A to B. Consumers of whale products gain area ABCF. Conservation interests lose area ABDE. The net loss to society would be area FCDE. How large or small this loss would be is an empirical question. (c) A minimum population level above the free market outcome incentivizes illegal harvest. Consider three possible safe minimum population levels: N_min (below market equilibrium), N_min1 (between market equilibrium and the social optimum), and N_min2 (above the social optimum). At N_min, trade could increase social welfare by moving in the direction of the social optimum but would stop short at point A with no incentive for illegal harvest. The net gain is an artifact of setting the minimum population level below the market equilibrium and allocating rights to the harvest industry. With N_min1, Private Demand for Conservation is below the Demand for Whaling. At equilibrium population N_min1, the price wedge between Private Demand for Conservation and Demand for Whaling incentivizes illegal harvest. Illegal harvest would decrease the population further away from the social optimum. 
Incentives for illegal harvest are larger at N_min2 (a larger wedge). Illegal harvest and associated decreases in the whale population could move the population toward (and not away from) the social optimum. This perversion suggests that welfare gains are not associated with the whale share program but rather with the way it happens to create incentives for illegal harvest that end up pushing the system closer to the social optimum. Of course, depending on the extent of illegal whaling, the population could diminish below the social optimum, and social welfare could be lower. At N_min1 and N_min2, demand growth exacerbates these problems, creating larger price incentives for illegal harvest. 


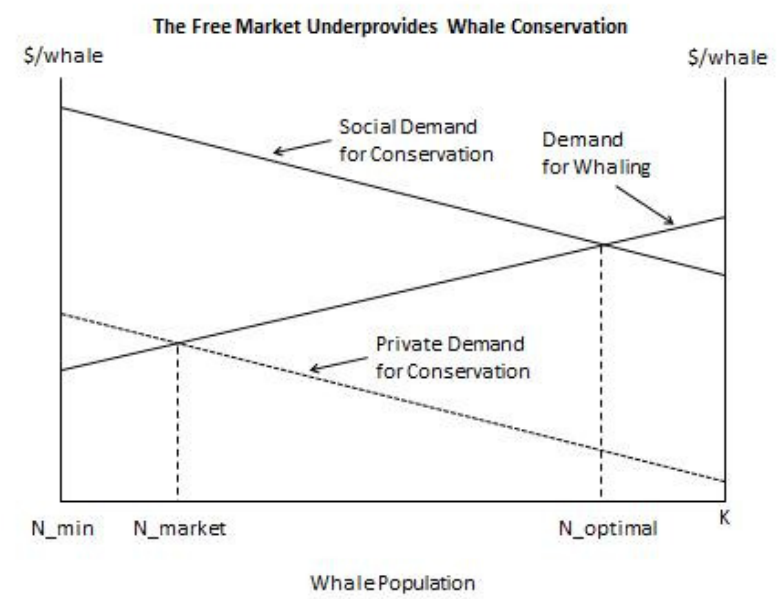

(a)

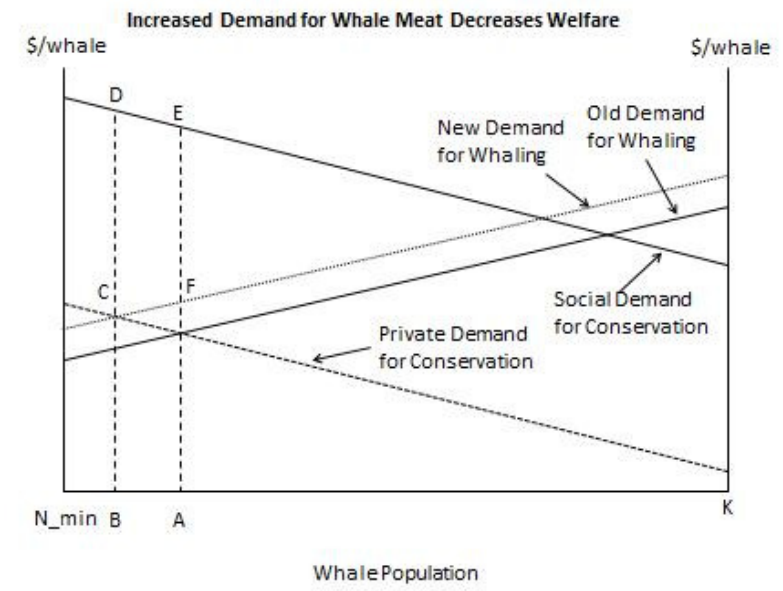

(b)

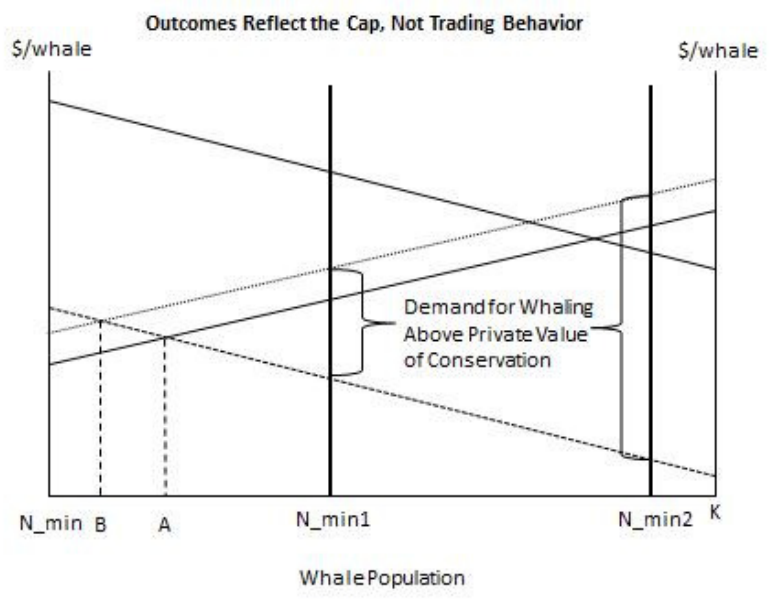

(c)

Figure 1 - Market outcomes and the social optimum. 